STUDI

FRANCESI

\title{
Studi Francesi
}

Rivista quadrimestrale fondata da Franco Simone

160 (LIV | I) | 2010

II simbolismo. Nomi, aspetti, momenti. Studi in memoria di Ivos Margoni

\section{Alain Romestaing, Jean Giono. Le corps à l'œuvre}

\section{Elisa Borghino}

\section{OpenEdition}

Journals

Edizione digitale

URL: http://journals.openedition.org/studifrancesi/7350

DOI: $10.4000 /$ studifrancesi.7350

ISSN: 2421-5856

\section{Editore}

Rosenberg \& Sellier

\section{Edizione cartacea}

Data di pubblicazione: 1 avril 2010

Paginazione: 184

ISSN: 0039-2944

Notizia bibliografica digitale

Elisa Borghino, «Alain Romestaing, Jean Giono. Le corps à l'œuvre», Studi Francesi [Online], 160 (LIV | I) | 2010, online dal 30 novembre 2015, consultato il 10 janvier 2021. URL: http://

journals.openedition.org/studifrancesi/7350 ; DOI: https://doi.org/10.4000/studifrancesi.7350

Questo documento è stato generato automaticamente il 10 janvier 2021.

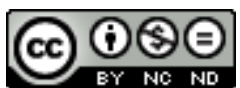

Studi Francesi è distribuita con Licenza Creative Commons Attribuzione - Non commerciale - Non opere derivate 4.0 Internazionale. 


\title{
Alain Romestaing, Jean Giono. Le corps à l'œuvre
}

\author{
Elisa Borghino
}

\section{NOTIZIA}

ALAin ROMESTAING, Jean Giono. Le corps à l'œuvre, Paris, Champion, 2009, pp. 446.

1 Il saggio di Alain Romestaing si apre con una citazione di Jean-Jacques Courtine. Per lui evocare il corpo nel testo significa richiamare i profondi sconvolgimenti e le trasformazioni vissute per la prima volta in quel ventesimo secolo cui si deve l'invenzione teorica del corpo. Proprio nella scia di tale riflessione si pone l'opera di Giono, non solo perché la corporeità è al tempo stesso tema e motivo di predilezione dei suoi scritti, ma anche perché essa mette in atto un lavoro continuo e incessante sulla scrittura.

2 Obiettivo di Romestaing, docente di letteratura francese all'IUT dell'Università Descartes di Parigi, è l'analisi della funzione del corpo nell'opera di Jean Giono. Attraverso le tre grandi parti che lo compongono - Il corpo nei racconti, il corpo nel mondo, il corpo e il nulla -, lo studio si propone di interrogare la corporeità in quanto assoluta protagonista delle opere di Giono. Portatore di una visione del mondo e della condizione umana tanto coerente quanto complessa, il corpo di Giono gioca infatti sull'alternarsi di presenza e assenza, realtà e finzione, rendendo possibile la creazione di personaggi originali e la ridefinizione del soggetto umano che, gettato nell'universo, assume una libertà sempre maggiore anche a scapito di una profonda solitudine e lacerazione.

3 La corporeità incide quindi in modo fondamentale sulla scrittura, la quale si attiva proprio grazie a quel corpo che ne esprime tanto il potere quanto i limiti. Emerge così il profondo intreccio esistente tra filosofia ed estetica, che per Giono si dimostrano indissolubilmente legate. Il rapporto instaurato dai suoi personaggi con l'universo rispecchia la reale difficoltà dello scrittore, quell'individuo estraneo al mondo reale che 
si pone a sua volta come un essere incapace di nuotare. Sarà ancora una volta solo attraverso il corpo che l'autore riuscirà ad attraversare quel fiume che separa la realtà dalla finzione, laddove la corporeità rispecchia il tentativo di Giono di fuggire dal reale, facendo solo temporaneamente e parzialmente del testo un canto del mondo. È proprio in qualità di artista ed inventore che Giono mette in atto tale superamento, interrogando il corpo e mettendolo alla prova. Come un vero e proprio disegnatore, Giono colpisce per la varietà degli approcci descrittivi, che ritraggono l'individuo nella sua difficoltà di rapportarsi con l'ambiente che lo circonda.

4 Il corpo non è altro che la metafora vivente dell'opera di Giono. Non è tanto il suo posto nel testo, quanto il posto del corpo nel mondo ad essere privilegiato. Esso permette d'interrogare, di sondare i limiti dell'umano, rendendo giustizia a quell'ambivalenza propria dell'individuo che tenta di districarsi - come suggeriscono i forti richiami del testo a Paul Ricœur - tra realtà, mondo e verità. 